\title{
Case study: Student's response towards online learning in Engineering Education during COVID-19 Pandemic
}

\author{
Rashpinder Kaur ${ }^{1}$, Arshia Garg ${ }^{2}$, Prinkaldeep Kaur ${ }^{3}$ \\ ${ }^{1,2,3}$ Department of Electronics and Communication Engineering, \\ Chitkara University Institute of Engineering and Technology, Punjab, India \\ rashpinder.kaur@chitkara.edu.in \\ 2arshia172108.ece@chitkara.edu.in \\ 3prinkal2727@gmail.com
}

\begin{abstract}
Novel Corona virus Disease (COVID-19) originated from Wuhan, China is widespread across the world so World Health Organization has declared COVID-19 as pandemic. As there is no vaccine available and this disease is transmitted though air so social distancing is one of the widely adopted strategy to control the spread of the COVID-19 pandemic. The education process all over the country was suspended due to announcement of National Lockdown in April, 2020 by the government of India. The Teaching Organizations and Management of Engineering Colleges and Universities in India during this Lockdown Period took initiative to continue education and teaching with Information Technology. This study attempted to investigate the quality of engineering education through online platforms in terms of knowledge gain, concept clarity, assessment, satisfaction level of students during the COVID-19 pandemic. An online survey was conducted and 123 student's responses were received. The student's response towards the online learning leads to conclusion that although the use of technologies in education is increased a lot but still learning through online mode will remain as supplementary material for the students. It cannot replace the traditional classroom teaching.
\end{abstract}

\footnotetext{
Rashpinder Kaur

Department of Electronics and Communication Engineering, Chitkara University Institute of Engineering and Technology, Punjab, India

rashpinder.kaur@chitkara.edu.in
}

Keywords: Online learning, Pandemic, Technology

\section{Impact of technology in Education during Pandemic}

Increased use of technology in education during the pandemic is not a new idea; it has been in execution since several years via different means such as distance learning, blended learning, flipped learning, e-learning etc (Technology, 2012). In 1970s, the first time use of technology in the field of education in India is done through the Satellite Instructional Television for educational broadcasting over the radio to provide uniform access of knowledge to all the learners. The National Mission on Education through Information and Communication Technology was launched by the government of India in 2009 to enhance the teaching and learning process in Higher Education. The main objective behind this mission was to develop world class standardized e-content to meet aspirations and personalized needs of the every learner, also making it available free of cost to them (Pegu, 2014).

COVID-19 brought a "second wind to higher education in India." The education system is transiting in India from face-to-face learning to online learning; following the education models applied in various countries viz. UK, US during this emergency situation to provide education to every student. In this hard period, the private companies such as Microsoft, Google and Zoom are providing various features in their products like video conferencing, recording 
functionality, etc. for free and extending user limits, video call limits for Educational customers through July 1, 2020' (Shenoy et al., 2020) . The educational institutions are receiving continuous support from the government and conducting classes through online platforms like go to webinar, zoom, google meet, Microsoft teams etc. One of the survey conducted on the current situation of India on digital transformation revealed that large population of India use mobile hotspot to access the internet. 96 percent are students among this population are facing issues of internet connectivity when they use mobile hotspots to access educational resources(Ansari \& Tripathi, 2017). These issues can be resolved with provision of connecting internet connectivity through various services such as Landline or Direct to home or cable networks. The cities or areas where there is facility of high bandwidth for internet connection can offer this internet facility to remote areas so that students of remote areas can also access online educational resources.

To overcome these internet issues and to provide education to every student who can't afford smart phones, The Union human resources development (HRD) Ministry has launched channels like swayam prabha as free to air channel on various direct to home (DTH) platforms like Tata sky, Airtel, Dish TV, and Jio TV app. At present 15 million students are enrolled in various courses broadcasted through these channels(Majumder \& Sarma, 2010) .

We have discussed the availability of resources to provide online education to the students in this pandemic situation. But the practical knowledge or laboratory skills in engineering which is major part is still lacking during this situation because it require equipments, experimental kits, hands-on experience. Lots of engineering innovations have been developed for engineering laboratories can be explored and utilized to compensate the practical skills of engineering students. The next section will be discussing the availability of virtual instrumentation/virtual labs to provide practical knowledge to engineering students.

\section{Scope of enhancement in practical skills of students during Pandemic using Innovations in Engineering Laboratories}

Practical skills are essential in engineering education. Hands-on laboratory experience in engineering laboratories plays a significant role in developing these skills of engineering graduates. It is already discussed that online platforms are utilized to provide education to the students during Pandemic. To provide lab courses using online platform, various types of softwares like LabVIEW, Multisim and MATLAB are utilized as tools in virtual labs (Raman et al., 2011 ). The virtual labs are designed by various Indian Institute of Technologies (IIT's) Kharagpur, Mumbai, Kanpur, Delhi etc. Students can perform experiments online while sitting at home using this virtual instrumentation platform.

Augmented reality (AR) is another emerging technology in the field of engineering education to provide real time interactive experience along with virtual instrumentation experience to engineering students. Augmented reality (AR) is blend of virtual and physical instruments, using 3D modeling, animations and interactive media; it can be helpful for students to understand the complex engineering concepts. This technology is also helpful in visualization of internal operations performed in the embedded system, which cannot be possible to visualize in real time scenario. One of the engineering innovations developed in AR/VR laboratory of Chitkara University, Punjab, India is AR learning system in which students can work with the virtual replicas of two laboratory equipments that are function generator and oscilloscope. These two equipments are essential for electronics students to observe/display the variation of voltage/current waveforms with respect to time on a two-dimensional plot(Singh et al., 2019). Students can generate different waveforms such as sinusoidal wave, square wave, or triangular wave. Students can operate these virtual instruments using mouse in AR learning environment. An information bar in the interface of AR learning system displays supplementary information about the use of buttons and knobs of instruments. The virtual model of oscilloscope is shown in fig. 1

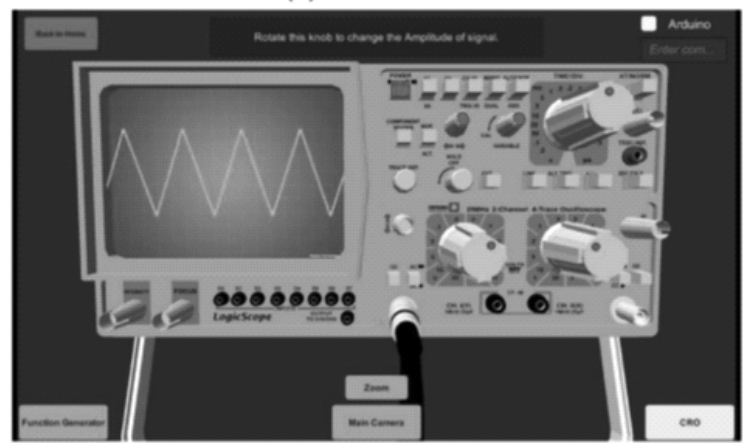

Fig.1 : Virtual model of oscilloscope in AR learning environment 
This system is using learner centered approach so that students can get maximum benefit of learning and the teacher act here as facilitator. To enhance practical learning experience of students during this pandemic, this system can be utilized by the engineering faculty. The teacher can do set up of this system in the laboratory and students can learn the operation of these equipments and perform various experiments like measurement of amplitude, frequency, time, experiments of rectifiers etc., using this system in online mode while staying at home. The experimental set up of AR learning system is shown in fig. 2 .

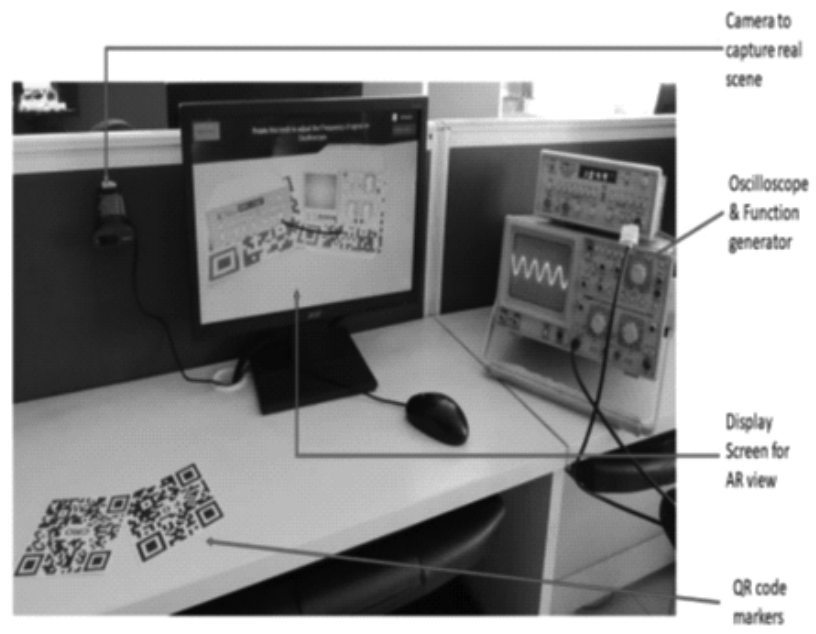

Fig.2 : Experimental set up of AR learning system

Another innovation in AR/VR lab is the development of embedded learning system for interactive learning and relating the practical knowledge to theoretical concepts. This system

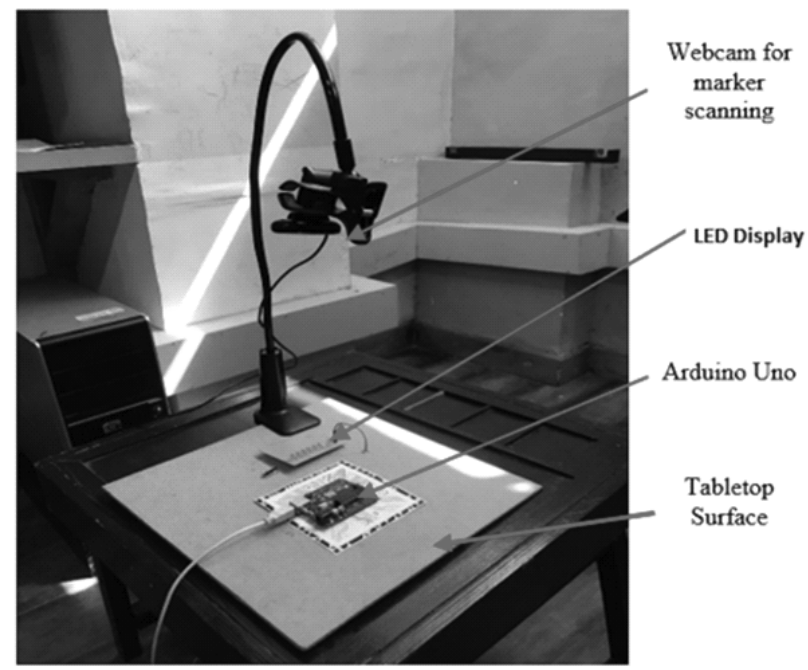

Fig 3(a) : Experimental setup of embedded sytem using arduino Uno board

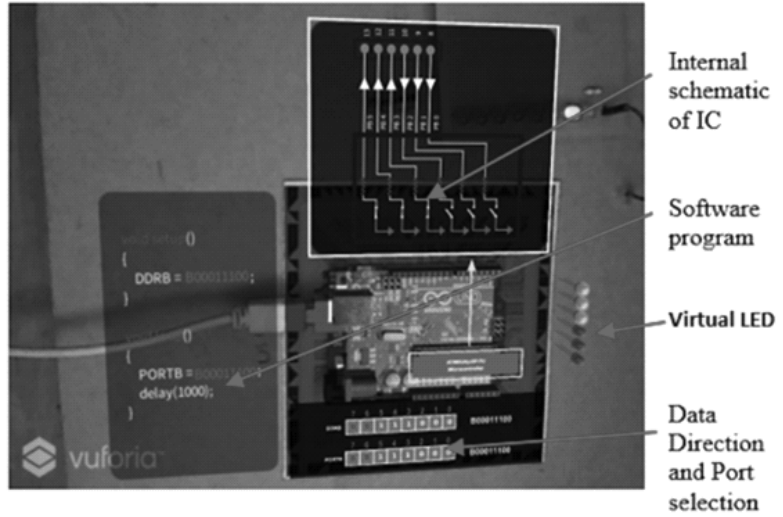

Fig.3(b) : Execution of program of blinking LED using embedded system in AR learning environment

consists of hardware components like computer in which AR application is used, the tabletop surface which is used for real time interaction, webcam to show visual content, (Kumar et al., 2020). The experimental set up of embedded system and display mode of execution of code of blinking LED in AR learning environment is shown in fig.3(a) and (b) respectively.

The student can learn pin configuration of ATmega microcontroller, interfacing of analog and digital devices with arduino with the help of this system. In the traditional laboratories, students were struggling with the hardware kit of embedded system and could not see the internal operations. This system is helpful in solving these issues of students and can improve the learning efficiency of students.

These two systems developed in augmented reality can be utilized by the engineering faculty to provide virtual laboratory experience to students sitting at home. As we know that the learning experience of students is more effective with face to face interaction but limitation in that environment is that sometimes there are less equipments in lab in comparison to student's strength. Secondly, some students damage the hardware kits due to lack of training in using these kits. So this kind of learning environments can train the students to use these tools effectively in online mode with better understanding in one to one (teacher and student) mode.

\section{Results of student's response on survey of online learning of students}

An online questionnaire (Roy et al., 2020) was developed using Google forms to get feedback of students on online learning. The link of the questionnaire was sent through emails and WhatsApp 
to the students. The student participants are first year and final year engineering students of Chitkara University, Rajpura, India. Only these students have selected for participation because the author has taught them and well acquainted with them. There were 10 multiple choice questions related to feedback of students on online learning experience like type of online platform, assessment, understanding level, satisfaction level etc. A total of 123 responses were recorded. The age of participants is between 18 to 21 years. The number of female student participants and male student participants are 31 and 92 respectively. The survey was divided into two parts: part I consists of 5 questions which can give insight of student's feedback on quality of online learning and assessment as compared to traditional offline classes and part II consists of 5 questions based on student's feedback on different platform used to access online education.

Part I: Response of students towards effective learning via online mode of delivery

The first question in the survey was to know about choosing the best feature about the online learning during this pandemic period. $62 \%$ and $59 \%$ of student participants have chosen first two features from the given features that are anytime anywhere learning and learning in safe, protected environment. 20 to $21 \%$ students have chosen other two features like less noise and disturbance free environment, learning with the use of technology.

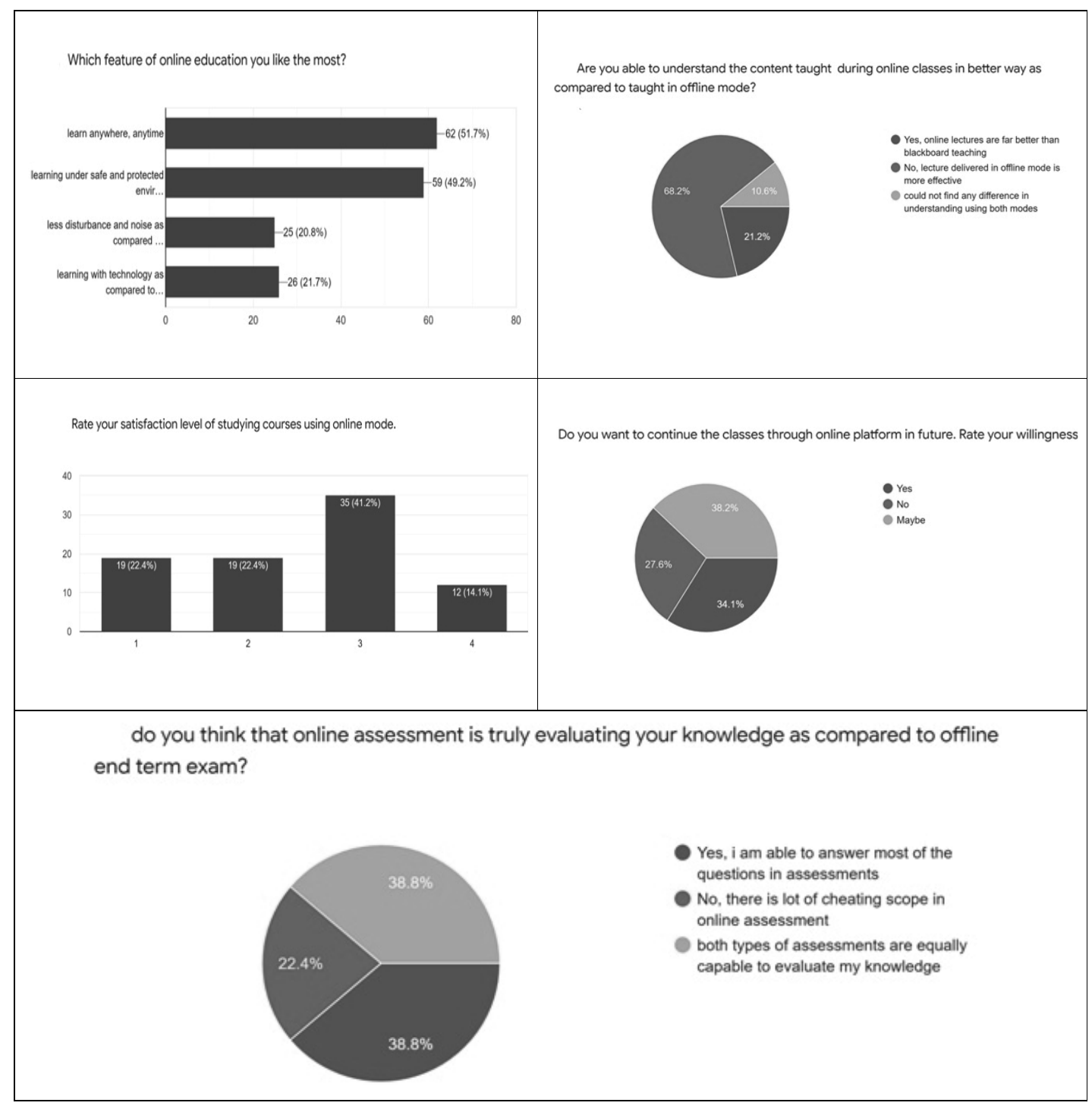

Fig. 4 : Response of students on quality of learning through online mode 
The second questions asked in this survey was whether the students able to understand the content in online classes in the same way as offline classroom teaching. The student's response for this question was very exclamatory. $68 \%$ of the students chosen the option that lecture delivered in offline mode is very effective as compared to online class. $21 \%$ students have chosen the option which states that online learning is far better than blackboard teaching. $10 \%$ of the students found no difference between online and offline teaching, they considered both as same.

When the question related to their knowledge evaluation using online assessment is asked, then students were happy with online assessment as $38 \%$ has chosen that they were able to answer all the questions asked in the online assessments and another $38 \%$ chosen both online and offline assessments equally effective in evaluating their knowledge. $22 \%$ of the students admitted that there is scope of cheating in online assessments due to less surveillance or invigilation.

When it is asked to rate their satisfaction level in online learning on 4 point Likert scale

\section{1: Poor, 2: Average, 3: Satisfied, 4: Very Satisfied}

Only $14 \%$ students have responded as very satisfied and $41.2 \%$ students (maximum) rated their online learning experience as satisfied. $22 \%$ students rated average satisfaction and $22 \%$ as poor satisfaction of online learning.

The last question in this category was to rate the student's willingness in continuing their classes in online mode. The $34 \%$ of students responded yes and $38 \%$ shows uncertainty by choosing maybe as option. Which indicates that if this pandemic remains then they have to choose online mode for learning as no other alternative is available. $27 \%$ of the students responded as no to online classes. The results are shown in fig. 4 .

Part II: Student's response towards use of platform for online lectures

The first question was about the utility of the various online platforms by the students. Go to webinar platform is used by large percentage $(85 \%)$ of students then Google classroom is used by $77 \%$ of student participants, then $48 \%$ and $43 \%$ students have used zoom and Microsoft teams platform to attend online classes. The total percentage of student participants in using platforms is higher than $100 \%$ because students have chosen more than single platform.

The second question was that out of these platforms, which one they considered as best platform for classes and which feature about that particular platform, they liked the most. The results indicated that Go to webinar platform is student's first choice as $47 \%$ students have chosen this as most likeable. 18\% students have chosen Google classroom as second best choice. The features about the software liked by the students are shown in table below:

Table I: summary of features liked by the students related to their most liked platform

\begin{tabular}{|c|c|c|}
\hline Sr.no & $\begin{array}{l}\text { Name of } \\
\text { platform }\end{array}$ & $\begin{array}{l}\text { Feature filled by the student in } \\
\text { survey form }\end{array}$ \\
\hline 1. & Go to webinar & $\begin{array}{l}\text { - Totally control by the } \\
\text { teacher } \\
\text { - All are muted } \\
\text { - In this platform, we don't } \\
\text { face any type of } \\
\text { misbehaviour. } \\
\text { - Its better then all of them } \\
\text { - Automatic Attendance } \\
\text { feature } \\
\text { - No one can interrupt the } \\
\text { session, less disturbance } \\
\text { - Features like raising a } \\
\text { hand while you have a } \\
\text { doubt, } \\
\text { - asking } \\
\text { personally to the teacher } \\
\text { using chat box }\end{array}$ \\
\hline 2. & $\begin{array}{l}\text { Google } \\
\text { Classroom }\end{array}$ & $\begin{array}{l}\text { - Easy to share the screen } \\
\text { - Easy to share our doubts in } \\
\text { front of all class by unmute } \\
\text { the microphone. } \\
\text { - Good understanding of } \\
\text { lecture } \\
\text { - To-do, informed all tasks up } \\
\text { to date } \\
\text { - Easy user interface } \\
\text { - Attendance System through } \\
\text { Message }\end{array}$ \\
\hline 3. & Google meet & $\begin{array}{l}\text { Its more efficient as Google } \\
\text { meet asks before joining the } \\
\text { class about switching on/off } \\
\text { camera and microphone }\end{array}$ \\
\hline
\end{tabular}

The next question asked to the students that how many of them are learning through the online portals provided by government and IIT's viz. swayam, virtual labs, NPTEL, National digital library etc. $71 \%$ of student participants have chosen swayam courses, 
$22 \%$ students are studying through NPTEL courses, $20 \%$ students have accessed national digital library (NDL), only $8 \%$ have accessed virtual labs.

The last question in this part was to rate their online learning experience with digitization of education on 4 point Likert scale

\section{1: Poor, 2: Average, 3: Good, 4: Very Good.}

$17 \%$ of students rated this online learning experience through digitization as very good, $42 \%$ has chosen good experience, $23 \%$ had average experience and $16 \%$ students had poor experience of learning. The results are shown in fig.5.
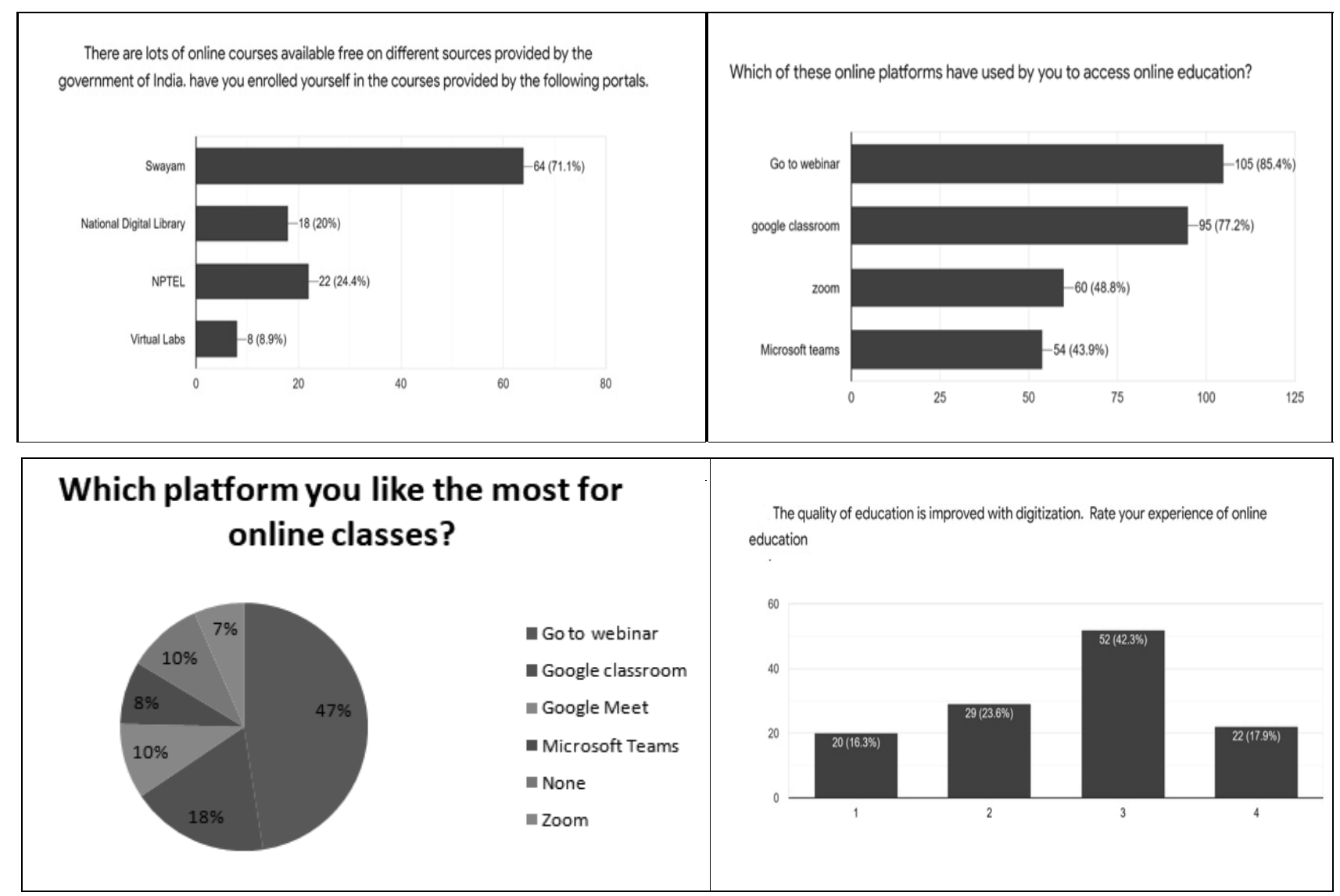

Fig. 5 : Response of students on quality of platforms for online mode of learning

\section{Discussions on student's response to online learning}

The student's response on their online learning experience has revealed information which can be helpful for the teachers to overcome the issues faced by the students and can give inputs to improve the quality of online education. These responses of students revealed that majority of the students likes to learn whenever they want to be without any physical boundaries of classroom. The second observation is their awareness about the corona virus spread. They liked to continue their learning while staying in safe zones i.e. their home. The noise factor, use of innovative technology as compared to chalk and talk methods are not on priority list for students in this pandemic time, so these factors are suppressed. The major observation seen through student's feedback is that large group of students were agreed with offline classroom teaching as compared to online mode. The students were comfortable with traditional teaching as they can understand more when teacher teach in front of the class and clarifying their doubts instantly. This feature is available in the online platform like Google classroom but some students were unaware about this feature or might feel hindrance in asking questions through the online platform due to lack of confidence. The poor or slow network connectivity is also major issue in live online classes which force student sitting at his remote place to miss that topic and lose interest in that topic. Sometimes the voice quality also affected which causes inability of students in 
understanding the lecture. Another drawback in online teaching is that as teacher is focusing on delivering the lecture though the PowerPoint so he is delivering the lecture and does not bother that whether the student is able to understand or cope up with the pace of his lecture delivery. In the blackboard teaching, teacher delivers his lecture while facing the students in front of them so he is able to read student's face that whether they understood the lecture or not. These drawbacks of online teaching leads to student's less satisfaction with online learning as results in this paper also reported only $14 \%$ as very satisfying experience of learning through online mode. These all factors discussed above leads to reduce student's willingness in continuing their education through online mode. Only $34 \%$ students are genuinely willing to continue their studies through online mode.

The analysis of results of student's response on second part of questionnaire provides the knowledge of students about various online platforms, the various features of these platforms explored by them. This analysis also gives us information that students are also accessing national portals of engineering education to enhance their knowledge and concepts. The limitation seen in the analysis of results of second part was less rating of students to digitized learning experience. It shows that our education system is highly dependent on technology but still students are more satisfied with face to face learning and blackboard teaching.

\section{Conclusion}

In this technological era, every human being in this world is dependent on technology for his daily needs like food, education, entertainment etc. everyone is equipped today with smart phones, tablets, smart TVs etc. Lots of mobile applications to meet individual needs are popping up every day. Lots of interactive educational applications like byju learning, educational you tube channels and videos are available for online study. But still students preferred normal teaching where teacher teach his class in front of them. This paper explored the experience of engineering students of studying through online platforms during pandemic period using online survey questionnaire. The results gave us deep insight of student's psychology related to learning through online mode. The response of students in this survey raised various questions on quality of online learning due to their less interest in online mode, less rating to online learning and less willingness to continue their studies through online mode. The engineering educators should look after these issues by making classes more interactive and innovative teaching methods. The teachers should be pro-active and connected to the students more during his online classes so that students will have better understanding and learning experience.

\section{References}

[1]Ansari, M. S., \& Tripathi, A. (2017). An investigation of effectiveness of mobile learning apps in higher education in India. International Journal of Information Studies and Libraries, 2(1), $33-41$.

[2]Kumar, A., Mantri, A., \& Dutta, R. (2020). Development of an augmented reality-based scaffold to improve the learning experience of engineering students in embedded system course. Computer Applications in Engineering Education, $\mathrm{O}$ c t o b e r $2019, \quad 1-14$. https://doi.org/10.1002/cae.22245

[3] Majumder, A. J., \& Sarma, G. K. (2010). Open Courseware initiatives for e-learners in India. http://arizona.openrepository.com/arizona/handle $/ 10150 / 224211$

[4]Pegu, U. K. (2014). Information and communication technology in higher education in India: Challenges and opportunities. International Journal of Information and Computation Te c hnolog y, 4 ( 5 ), $513-518$. http://www.irphouse.com/ijict.htm

[5]Raman, R., Nedungadi, P., Achuthan, K., \& Diwakar, S. (2011). Integrating Collaboration and Accessibility for Deploying Virtual Labs using VLCAP. International Transaction Journal of Engineering, Management, \& Applied Sciences \& Technologies, 2(5), 547-560.

[6]Roy, D., Tripathy, S., Kar, S. K., Sharma, N., Verma, S. K., \& Kaushal, V. (2020). Study of knowledge, attitude, anxiety \& perceived mental healthcare need in Indian population during COVID-19 pandemic. Asian Journal of Psychiatry, 51 (A pri1), 102083 . https://doi.org/10.1016/j.ajp.2020.102083

[7] Shenoy, V., Mahendra, S., \& Vijay, N. (2020). COVID 19 Lockdown Technology Adaption, 
Teaching, Learning, Students Engagement and Faculty Experience. Mukt Shabd Journal, 9(4), 698-702. https://www.researchgate.net/ publication/340609688

[8] Singh, G., Mantri, A., Sharma, O., Dutta, R., \& Kaur, R. (2019). Evaluating the impact of the augmented reality learning environment on electronics laboratory skills of engineering students. Computer Applications in Engineering
Education, $27(6), 1361-1375$. https://doi.org/10.1002/cae.22156

[9] Technology, C. (2012). Adoption of Web 2.0 technology in higher education: A case study of universities in National Capital Region, India Sunil Tyagi Ministry of Health \& Family Welfare, Government of India. International Journal of Education and Development Using Information and Communication Technology, 8(2), 28-43. 